\title{
Trend of HIV Prevalence in Pregnant Women Attending Antenatal Care Clinic at Faith Alive Foundation and Hospital, Jos, Plateau State
}

\author{
Anyaka Charles ${ }^{1,2}$, Ocheke Amaka ${ }^{1}$, Oyebode Tinuade ${ }^{1}$, Isichei Mercy ${ }^{2,4}$, Anyaka Ifechi ${ }^{5}$, \\ Isichei Christian $^{2,3}$ \\ ${ }^{1}$ Department of Obstetrics and Gynaecology, University of Jos, Jos University Teaching Hospital, Jos, Nigeria \\ ${ }^{2}$ Faith Alive Foundation and Hospital, Jos, Nigeria \\ ${ }^{3}$ Department of Chemical Pathology, University of Jos, Jos University Teaching Hospital, Jos, Nigeria \\ ${ }^{4}$ Department of Surgery, University of Jos, Jos University Teaching Hospital, Jos, Nigeria \\ ${ }^{5}$ Our Lady of Apostles Hospital, Jos, Nigeria
}

Email address:

charlesanyaka@yahoo.com (A. Charles)

\section{To cite this article:}

Anyaka Charles, Ocheke Amaka, Oyebode Tinuade, Isichei Mercy, Anyaka Ifechi, Isichei Christian. Trend of HIV Prevalence in Pregnant Women Attending Antenatal Care Clinic at Faith Alive Foundation and Hospital, Jos, Plateau State. European Journal of Preventive Medicine. Vol. 4, No. 3, 2016, pp. 61-64. doi: 10.11648/j.ejpm.20160403.12

Received: February 8, 2016; Accepted: February 21, 2016; Published: April 8, 2016

\begin{abstract}
Objective: HIV prevalence data from pregnant women who attended Antenatal Care Clinic over a five year period were used in the Prevention of Mother-To-Child Transmission (PMTCT) of HIV programmes and remain useful for Prevention, Care, Treatment and Support of pregnant women and ensuring that the goal of zero transmission is met. It also helped policy makers to take appropriate action in HIV/AIDS programmes. Methodology: A descriptive study of pregnant women presenting for the first time at the antenatal clinic of Faith Alive Foundation and Hospital, Jos from $1^{\text {st }}$ January 2010 to $31^{\text {st }}$ December 2014 was carried out. Information regarding age, gestational age at booking, parity and HIV sero status of the clients were analyzed. Screening test was carried out in a serial two step approach using determine and UNIGOLD as the confirmatory test while stat pack was the tie-breaker with discordant result. Positive samples were confirmed by western blot method. Result: A total of 1720 pregnant women were registered in the antenatal unit of Faith Alive Foundation and Hospital, Jos from 1st January 2010 to $31^{\text {st }}$ December 2014. 120 were sero positive. The overall HIV prevalence rate was $6.9 \%$. High prevalence rate were observed in those aged 20-39 years. There was a decline in HIV prevalence from $10.7 \%$ in 2010 to $6.8 \%$ in 2013 and $5.8 \%$ in 2014. Majority of the sero positive women booked early in pregnancy, within the $1^{\text {st }}$ and $2^{\text {nd }}$ trimesters from $77.8 \%$ in 2010 to $80 \%$ in 2014. Conclusion: A decline in HIV prevalence was observed during the five year period. The study also revealed that significant number of HIV positive antenatal women registered for antenatal care early. The overall HIV sero prevalence is still high. There is need to astronomically scale up our intervention approach against HIV infection.
\end{abstract}

Keywords: HIV Prevalence, Antenatal Clinic, PMTCT, HIV Testing and Counselling, Faith Alive Foundation

\section{Introduction}

The burden of mother-to-child-transmission (MTCT) of HIV is much higher in sub-Saharan Africa due to higher level of heterosexual transmission, high male: female ratio, high total fertility rate and high levels of breastfeeding [1]. Nigeria has the largest burden in the West Africa sub-region with about 2.98 million people living with HIV [2].

Though HIV prevalence in Nigeria is on the decline with an estimated HIV prevalence of 3.4\% [3], Nigeria still has the largest HIV disease burden in the sub region as well as the second highest in the world on account of her large 
population [4]. This portends negative impact on our economic development due to deterioration in child survival rates, decreasing life expectancy, increasing numbers of orphans and strain on the weak health system $[1,4]$.

If MTCT is not checked the increasing number of AIDS related deaths in Nigeria may reverse the gains made in child survival $[2,3]$.

The high prevalence of HIV among pregnant women, high total fertility rate, culture of prolonged breast feeding/mixed feeding, non-use of modern health facilities for antenatal and delivery purpose have contributed to the high rate of MTCT in the country [5].

HIV prevalence data from prevention of mother-to-childtransmission (PMTCT) programmes are being utilized to monitor the trend of HIV epidemics that helps policy makers to take appropriate action [6].

Despite the multi-sectional response to HIV and the promotion of combination prevention what HIV counseling and testing as an entry into treatment, care and support, coverage has remained low especially in rural areas and among pregnant women with Nigeria having least HIV indicators in Africa [3, 5].

The objective of this study was to determine the trend of HIV prevalence among antenatal clients in this facility between January 2010 and December 2014. No previous study in this area has been done in Faith Alive Foundation (FAF) and any other hospital in Plateau State, North Central Nigeria. FAF was established in 1996 to meet the holistic health and social services needs of the less privileged including Persons Living Positively at no cost to them.

\section{Materials and Method}

A descriptive study was done amongst the patients who booked for antenatal clinic in Faith Alive Foundation and clinic between $1^{\text {st }}$ January 2010 to $31^{\text {st }}$ December 2014 .

Faith Alive Foundation (FAF) is located in Jos Plateau state, North Central Nigeria.

Screening test was conducted in a serial two step approach using Determine HIV test kits and UNIGOLD HIV kits after appropriate pre-test counseling with informed consent. Discordant results were subjected to statpak for confirmation. However all positive samples were confirmed with western blot method.

Information regarding HIV sero status age, parity and gestational age at booking of the clients were analysed.

Data were entered and analysed using Epi-info statistical software.

\section{Results}

Table 1: Shows a progressive decline in prevalence percentage from $10.7 \%$ in 2010 to $6.2 \%$ in 2012 and $5.8 \%$ in 2014.

A total of 1720 women registered for antenatal clinic over the period and total of 120 were sero positive giving a prevalence rate of $6.98 \%$.

Table 2 shows most of the sero-positive clients booked in the second trimester (14-26 weeks) from 55.6\% in 2010 down to $48 \%$ in 2012 and $66 \%$ in 2014 . It also shows that most of the sero positive clients had booked within the 1 st and 2 nd trimester.

Table 1. HIV Positive status at booking.

\begin{tabular}{lllll}
\hline Year & HIV +ve & HIV -ve & Total & Percentage \\
\hline 2010 & 18 & 150 & 168 & 10.7 \\
2011 & 19 & 197 & 216 & 8.8 \\
2012 & 25 & 340 & 365 & 6.8 \\
2013 & 28 & 427 & 455 & 6.2 \\
2014 & 30 & 486 & 516 & 5.8 \\
Total & 120 & 1600 & 1720 & 6.98 \\
\hline
\end{tabular}

Table 2. Age at booking with HIV Status.

\begin{tabular}{|c|c|c|c|c|c|c|c|c|c|c|}
\hline \multirow{2}{*}{ Years } & \multicolumn{2}{|c|}{2010} & \multicolumn{2}{|l|}{2011} & \multicolumn{2}{|c|}{2012} & \multicolumn{2}{|l|}{2013} & \multicolumn{2}{|c|}{2014} \\
\hline & $+\mathrm{ve}$ & -ve & $+\mathrm{ve}$ & -ve & $+v e$ & -ve & +ve & -ve & $+v e$ & -ve \\
\hline $15-19$ & - & 3 & 1 & 6 & 1 & 5 & 2 & 6 & 2 & 5 \\
\hline $20-24$ & 3 & 20 & 2 & 34 & 4 & 77 & 2 & 90 & 4 & 87 \\
\hline $25-29$ & 8 & 58 & 7 & 79 & 9 & 99 & 10 & 136 & 9 & 130 \\
\hline $30-34$ & 5 & 44 & 6 & 57 & 4 & 73 & 5 & 108 & 6 & 158 \\
\hline $35-39$ & 2 & 23 & 2 & 12 & 4 & 53 & 4 & 79 & 5 & 92 \\
\hline $40-44$ & - & 2 & - & 5 & 3 & 25 & 4 & 5 & 3 & 8 \\
\hline $45-49$ & - & - & - & 4 & - & 8 & 1 & 3 & 1 & 5 \\
\hline Total & 18 & 150 & 19 & 197 & 25 & 340 & 28 & 427 & 30 & 486 \\
\hline
\end{tabular}

Table 3. Gestational Age at booking with HIV status.

\begin{tabular}{|c|c|c|c|c|c|c|c|c|c|c|}
\hline \multirow{2}{*}{ Weeks } & \multicolumn{2}{|c|}{2010} & \multicolumn{2}{|c|}{2011} & \multicolumn{2}{|c|}{2012} & \multicolumn{2}{|c|}{2013} & \multicolumn{2}{|c|}{2014} \\
\hline & $+v e$ & -ve & +ve & -ve & +ve & -ve & + ve & -ve & +ve & -ve \\
\hline$<13$ & 4 & 35 & 6 & 13 & 9 & 44 & 7 & 50 & 6 & 53 \\
\hline $14-26$ & 10 & 76 & 8 & 126 & 12 & 232 & 15 & 286 & 18 & 304 \\
\hline $27-40$ & 4 & 39 & 5 & 58 & 4 & 64 & 6 & 91 & 6 & 129 \\
\hline Total & 18 & 150 & 19 & 197 & 25 & 340 & 28 & 427 & 30 & 486 \\
\hline
\end{tabular}


Table 4. Parity at booking with HIV status.

\begin{tabular}{lllllllllll}
\hline \multirow{2}{*}{ Parity } & $\mathbf{2 0 1 0}$ & & $\mathbf{2 0 1 1}$ & & $\mathbf{2 0 1 2}$ & $\mathbf{2 0 1 3}$ & \multicolumn{2}{c}{ 2014 } \\
\cline { 2 - 11 } & + +ve & -ve & +ve & -ve & +ve & -ve & +ve & -ve & +ve & -ve \\
\hline 0 & 5 & 33 & 6 & 56 & 7 & 101 & 4 & 127 & 7 & 149 \\
1 & 5 & 56 & 8 & 62 & 8 & 99 & 7 & 119 & 9 & 140 \\
2 & 3 & 28 & 4 & 42 & 2 & 63 & 3 & 82 & 4 & 93 \\
3 & 2 & 13 & 3 & 19 & 62 & 37 & 4 & 56 & 5 & 61 \\
4 & 1 & 6 & 2 & 9 & 4 & 20 & 7 & 21 & 2 & 23 \\
Grand mulitpara* & 2 & 14 & 3 & 9 & 2 & 20 & 3 & 22 & 3 & 20 \\
Total & 18 & 150 & 19 & 197 & 25 & 340 & 28 & 427 & 30 & 486 \\
\hline
\end{tabular}

$* \geq 5$

\section{Discussion}

Our study shows an average sero prevalence over the study period of $6.98 \%$. This is much higher than the $3.4 \%$ HIV prevalence in Nigeria [3]. It is equally higher than the $3.29 \%$ reported in Jos [7] by Sagay et al, and 5.9\% reported over a $3 y r$ study period in Kano [8]. It is equally higher than the $5.4 \%$ reported over a 5 year study period in Bishoftu hospital Ethiopia [6]. This agrees with previous assertion that HIV sero prevalence shows large variation between and within regions and countries, moreso between high and low risk urban population [9].

Moreso Faith Alive Foundation and Hospital being known as mainly an HIV/AIDS hospital could have contributed to this increase slightly.

This study shows a trend in decline in HIV sero prevalence from $10.7 \%$ in 2010 through to $6.8 \%$ in 2013 and $5.8 \%$ in 2014. This decline is also noted among pregnant women in sub Saharan Africa and also similar to the finding in Kinshasa [10], Ethiopia [11] and North Uganda [12].

The persistently high burden of HIV and MTCT are indications that the national PMTCT programme has only made modest impact. This may be attributed to the low-level of coverage across the country [5]. To address this problem an accelerated scale-up plan 2010-2015 to rapidly decentralize PMTCT services in the country was developed and is being implemented $[13,14]$.

The study also shows that majority of the sero positive women booked early in pregnancy, that is within the 1 st and $2^{\text {nd }}$ trimesters from $77.8 \%$ in 2010 to $84 \%$ on 2012 and $80 \%$ in 2014. Late bookings in some cases may not allow enough time for some modes of intervention to be adequately implemented [15]. This observation is very encouraging if some of the targets of the 2010-2015 National PMTCT scale up plans are to be met which include, to ensure at least $90 \%$ of all pregnancy women have access to quality HIV counseling and testing by 2015 , to ensure to least $90 \%$ of all pregnancy women requiring ART for this own health receive life-long ART $[13,14]$. This will in no doubt help achieve the overall objective of PMTCT of HIV programmes of zero vertical transmission

The study shows a trend of increasing number of pregnant women counseled and tested and who also received their results which is similar to the observation of Agbogoroma et al [5].
The trend of declining prevalence of HIV from this study with the observation that majority of the HIV positive clients book early with the $1^{\text {st }}$ and $2^{\text {nd }}$ trimester are encouraging from this study.

The trends in HIV sero prevalence in this facility though declining is still high and can be lower. Apart from the need to astronomically scale up the intervention strategies, overcoming these challenges will require much political will and strategic commitment of national, state and local government resources and international support to addressing this problem.

There is therefore the need to involve all health care personnel and other stake holders like Traditional Birth Attendants in the ANC HIV screenings and PMTCT programmes as it has shown that Trained Birth Attendants when trained and well supervised can supplement efforts to provide PMTCT services in communities.

Faith Alive Foundation and hospital which offers service mostly to the less privilege including person living positively at no cost to them needs a lot of support in this direction if the target of the 2010-2015 National PMTCT scale up plan is to be achieved.

\section{Conclusion}

A decline in HIV prevalence was observed during the five year period. The study also revealed that significant number of HIV positive antenatal women registered for antenatal care early. The overall HIV sero prevalence is still high. There is need to astronomically scale up our intervention approach against HIV.

\section{References}

[1] Ogaji DS, Ikpeme BM, Oyo-Ita AE, Omuemu VO, Etuk S J, Ekabua JE. Awareness and acceptability of strategies for the prevention of mother to child transmission of HIV among antenatal clients in Calabar Nigeria. Niger J Med 2008; 17: 29-32.

[2] National Guidelines on prevention of mother to child transmission of HIV in Nigeria. 4th Ed FMOH Abuja Nigeria: FMOH; 2010 p. 1-133.

[3] Federal Ministry of Health 2012a: National HIV and AIDS and Reproductive Health survey report, Journal of HIV and Human reproduction (2014), vol. 2 issue 1, pg 15. 
[4] UNAIDS reports on the global AIDS Epidemic 2010. p. 10 Available from www.unaids.org/en/media/unaids/contentassets/documents/un aidspublication/2010/20101123_global report_en-pdf

[5] Agboghoroma C. O, Sagay AS, Ikechebelu JI Nigerian prevention of mother to child transmission of human immunodeficiency virus program: The journey so far. Journal of HIV and Human reproduction 2013 Jan- Jun, vol 1, issue 1 pg 1-7.

[6] Cherinet Y, Berihu A, Bekele A, Biadgilign S, Taye V, Tsegaye A Trend of HIV prevalence among pregnant women attending antenatal care unit of Bishoftu Hospital, Ethiopia. EthipMed J 2013 Jul; 51(3): 169-76.

[7] Sagay AS, Imade EG, Nwokedi EE Human immunodeficiency virus infection in pregnant women in Nigeria. International journal of Gynaecology \& obstetrics 1999; 66: 183-184.

[8] Galadanci H. S, Ilyasu Z, Tukur J, Muktar-Yola M, Adeleke SI Uptake of voluntary counselling and testing of HIV Pregnant women in a prevention of mother- to- child- transmission programme at Aminu Kano Teaching Hospital, Nigeria Afr J AIDS Res 2008. May 7(1): 143-8.

[9] Christian Isichie et al High rate of HIV Positives in a surgery focused medical outreach in Jos, Nigeria: Lessons from a provider initiated HIV counseling and testing. European Journal of Preventive Medicine 2015; 3(5): 137-140.
[10] Behets F, Edmonds A, Crabbe F, PTME Group. Heteregenous and decreasing HIV prevalence among women seeking antenatal care in Kinshasa democratic republic of Congo Int J Epidemol 2010. Aug; 39(4): 1066-73.

[11] Wolday D, Meles H, Hailu E, Messele T, Mengistu Y, Fekadu M, Parekh BS, Wuhib T. Temporary trends in the incidence of HIV infection in antenatal clinic attendees in Addis Ababa Ethiopia 1995-2003. J intern Med.2007 Feb; 261(2): 132-7.

[12] Fabiani M. Accorsi S, Lukwiya M, Rosolen T, Ayella E. O, Onek P. A, Declich S. Trend in HIV-1 prevalence in an antenatal clinic in North Uganda and adjusted rates for the general female population. AIDS 2001 Jan 5; 15(1): 97-103.

[13] Federal Ministry of Health. National scale up plan towards elimination of mother- to- child transmission of HIV In Nigeria 2010-2015- Abuja, Nigeria. Federal Ministry of Health; 2010.

[14] Federal Ministry of Health. National Health Sector strategic plan and implementation plan for HIV/AIDS 2010-2015. HIV/AIDS Division Abuja. Nigeria: Department of Public Health, Federal Ministry of Health; 2010.

[15] Agida ET, Abu P, Echikwonye M, Hwande TS, Ayeni HAD, Swende TZ. HIV prevalence among clients attending antenatal clinic at the federal medical centre Makurdi. Niger J Med 2010 Jul-Sept; 19(3) 295-7. 